\title{
Counting Library Holdings
}

Mr. Lyle is director, Louisiana State University Libraries.

I HAVE been asked by the executive secretary of the Association of Research $\mathrm{Li}$ braries and the editor of College and Research Libraries to write a short article on the recently issued report of the A.R.L. Committee on the Count of Library Holdings. Having been myself a member of the committee, my remarks can hardly be expected to be of a critical nature. Perhaps what I can most usefully do is to indicate the main steps which led up to the recommendations in favor of counting by physical volume and to reprint the directions for making such a count as formulated by the committee. For the details, the reader is referred to the report itself of which the writer has a limited number of copies for distribution.

The method of counting by bibliographical unit is described in detail by Robert B. Downs in his article entitled "Uniform Statistics for Library Holdings," published in the Library Quarterly for January 1946. That the method which Mr. Downs advocates will provide statistics (if the record is accurately and expertly kept) that are more reliable for comparative purposes than those based on other methods of counting can hardly be questioned; the danger lies in the conclusion that there is a method, or any method, of counting which will make for uniformity in statistics of libraries beyond a certain size. In view of the variations in library administrative procedures and in view of the complexity of materials received by university and large research libraries, it seems probable that no concept of uniformity in counting could be more than an ideal. ${ }^{1}$. If this is a correct assumption then it is an open question whether the bibliographical unit method of counting has advantages over present methods. Most libraries are now committed to a count by physical volume. If a change were made to bibliographical unit, a retroactive count would be necessary for these libraries and this would be burdensome and expensive. Secondly, the method of counting by bibliographical unit is much more complicated and more frequently calls for decisions by professional personnel than either a physical volume or piece count.

These things, among others, were apparent to the second A.R.L. Committee on the Count of Library Holdings ${ }^{2}$ which was appointed at the January I948 A.K.L. meeting on the motion of Robert Downs. The new committee's report, filed on Jan. 13, 1949, ${ }^{3}$ offered a brief résumé of earlier studies and pointed out the obvious but apparently overlooked fact that no adequate method of counting by physical volume had ever been formulated. To correct this situation the committee prepared a statement of the method of counting by physical volume (see Appendix I). ${ }^{4}$ After careful study of both systems it recommended its preference for the physical count because

1 Mr. Downs would appear to have reached this same conclusion. The minutes of the A.R.L. meeting of Mar. 3, 1949 report: "Mr. Downs, chairman of the earlier Committee on Statistics, said that he had once thought uniformity possible, but that he had now bethought uniformity possible, but that

2 Benjamin E. Powell, Jack Dalton, Rudolf Hirsch, Richard Logsdon and Guy R. Lyle.

3 Minutes of the 32 nd meeting of the A.R.L., Jan. 20, 1949, Appendix IV, p. 52 iff.

Appendices I and II appear at the end of this report. 
of its widespread use, simplicity and inexpensive administration., Since the ratio between the number of physical volumes and the number of titles in a library is to some extent indicative of the research character of a library, the committee recommended that university and large research libraries should also keep a count of acquisitions by title.

In preparing its report the committee borrowed heavily from the work of the earlier A.R.L. Committee headed by $\mathrm{Mr}$. Downs. Some of the specific instructions worked out by the Downs' committee were incorporated into the statement on counting by physical volume which is appended. The chairman of the A.C.R.L. Committee on Statistics and the Chief of the Library Service Division were invited to criticize the report and portions of their letters are reproduced in Appendix II. At the March I949 meeting of the A.R.L. a vote was taken on the two methods of counting with the result that 12 members favored counting by bibliographical unit and 29 by physical volume. On the basis of this vote and the discussion which followed, it seems probable that a few large libraries will continue to count their holdings and current acquisitions as they have always done, although a clear-cut majority appear to favor the method of counting by physical volume. Those who count by physical volume should use as a guide the instructions for counting set forth in Appendix I, those who count by bibliographical unit should follow the instructions set forth by Mr. Downs in the article previously noted. In reporting statistics, each library should designate which method it follows.

Although the committee has been discharged, it is my feeling (and, here, I cannot speak for the Committee) that the method of counting by physical volume will continue to be widely used in this country and that an effort should be made to improve and standardize the committee's statement. Thus, in the immediate future, I am more eager than ever for ideas and criticisms by letter of the method outlined in Appendix I. Criticism should be specific and, when possible, accompanied by carefully worded substitute provisions for the sections where it is felt that revision is needed.

\section{Appendix I}

\section{Outline of a Method of Counting by Physical Volume}

\section{Definition of a Volume}

A volume is defined as any printed or otherwise reproduced work, bound between two covers or suitable for being so bound.

\section{What to Count}

Only materials intended to form part of the library's permanent collection should be included. Temporary groups of material and other ephemera should be excluded.

All volumes cataloged or made fully available for use and intended for permanent addition to the collection should be included in the count. Thus all material which can be readily identified and located for use by cataloging, classification, finding-lists, checked bibliography, or a combination of these methods, would be counted, except such ephemera as noted above.

How and What to Count in the Total Volume Count

I. Count each volume as one.

2. When two or more volumes are bound together, count the resulting unit as one. For example, two, five, or a dozen pamphlets bound together between covers would count as one volume. 
3. 5 Serials should not be counted until they are bound in regular library binding or prepared for use by tying parts between board covers, placing parts in pamphlet boxes, etc. Count the latter in volumes as you would if they were bound in regular library binding. Serials awaiting regular library binding (e.g., latest volume of Atlantic or an older volume awaiting completion before binding) should not be counted.

A serial is defined as a "publication issued in successive parts, usually at regular intervals, and, as a rule, intended to be continued indefinitely."-A.L.A.

4. For comparisons of subject holdings, statistics of volumes shelved in professional school libraries, e.g., law, engineering, medicine, agriculture, business and journalism, etc., should be issued separately, as well as be included in the total volume count.

5. All libraries officially a part of an institution should be included in its statistics of holdings, regardless of location or administrative control.

\section{How and What to Count as a Separate Sta- tistic}

Separate statistics should be majntained for the following types of material and these statistics should not be included in the total volume count except in instances which are noted below in parentheses:

a. Manuscripts. Count by individual item.

5 Alternate to 3. Do not report the count of serials until they are bound in regular library binding. A serial is defined as a "publication issued in successive parts, usually at regular intervals, and, as a rule, inparts, usually at regular intervals, and, as a rule, intion: Unbound newspapers, intended for permanent keeping, shall be counted arbitrarily as 12 volumes a year for dailies and two volumes a year for weeklies.
A manuscript is defined as the smallest independent, self-contained unit in a collection. This may be a volume such as a ledger, scrapbook, or a letter press copy book; an individual letter or one sheet or a dozen sheets, etc. The physical characteristic of the manuscript decides whether it is one item or several items.

b. Micro-reproductions. Count microfilm by reel, strip or other physical form. Count photostats and photoprints by piece. (If the latter are bound in a volume or volumes, count by volume and include in the total volume count.)

c. Slides. Count individually.

d. Maps. Count unbound maps individually. (Count atlases and other bound collections of maps by volume and include in the total volume count.)

e. Motion picture film. Count by reel.

f. Sound recordings. Count by physical unit, e.g., cylinder, single-faced record, doublefaced record, or spool of wire.

g. Prints. Woodcuts, lithographs, engravings, etc. Count individually. (If prints come in a portfolio, with title page, count each portfolio as a volume and include in the total volume count.)

h. Music. Count by volume with exception that a score-a specific composition-with multiple playing parts should be counted as one volume regardless of how it is kept. Count instruction and method books as other books and include in the total volume count.)

i. Broadsides and posters. Count individually.

j. Other special categories of library materials, e.g., architectural drawings. Count individually.

\section{Appendix II \\ Excerpts from Letters}

From Ralph M. Dunbar, Chief, Service to Libraries, Office of Education, Feb. 17, 1949:

I. Will not the phrase "suitable for being so bound" in the Definition need some modification if "alternate 3 " is accepted? For example, serials tied up in board covers could certainly be considered as being suitable for binding, and hence by definition a "volume." I suppose that your "alternate 3 " simply eliminates serial volumes in this condition from being counted. The original definition may lead to confusion nevertheless.

2. Can some compromise be reached between " 3 " and "alternate 3 " of Appendix I? Original 3 seems too loose and the alternate too rigid. For example, serials placed loosely in pamphlet boxes are certainly liable to loss and damage and hence are rather nonpermanent in condition. On the other hand, it is possible that serials may be too fragile or other- 
wise unsuitable for binding, yet are amply protected in containers which have tapes or other forms of fasteners.

3. The recommendation (Appendix I, No. 5) that the holdings of all libraries officially a part of the institution be included in the total volume count is a good one, but some provision should be made for differentiating such libraries when they have their own budgets and their own staffs, separate and distinct from the general university library. Otherwise, university administrators will not have a comparable basis for estimating expenditure ratio, per student figures, etc.

4. In the matter of the definitions in Appendix I, we wonder if the "one sheet or a dozen sheets" part of (a) manuscripts could be sharpened up somewhat. The archivist may know how to interpret this part, but the layman may be puzzled by it. (e) Motion picture film. Our Visual Education Section questions the use of "reel" as a satisfactory unit for counting. The specialists suggest a counting by "prints" because "reel" is not a definite measure. They suggest that eventually librarians may wish to break down their film holdings by: $8 \mathrm{~mm}, 16 \mathrm{~mm}$, and $35 \mathrm{~mm}$. For the physical aspects involved in storage, the inflammable and the noninflammable character of the films is important, although it may not be so for the research librarian.

Our visual education specialists also ask why "filmstrips" are not specified for a count, as they form as important a medium as "slides." As you probably know, "filmstrip" is the term now being standardized by the trade and includes strip films and film slides, normally on $35 \mathrm{~mm}$ film, and five feet in length.

From G. Flint Purdy, Chairman, A.C.R.L. Committee on Statistics, Feb. 26, 1949:

... The method proposed in Appendix I seems to me to be about as far as we can go at the moment in establishing a standard and practicable means of measuring the contents of libraries. My personal preference is for Item 3 as approved by the majority of your Committee, rather than for the alternative suggestion. We actually bind all periodicals which we keep, but if we kept them in pamphlet boxes, for example, they would still constitute a part of our library resources and would be available through periodical indexes and abstracting journals.

I should like to see the suggested measurement of microfilm resources refined somewhat. Why could this not be done by using feet or frames as the unit rather than pieces?

I find the proposal with respect to counting music somewhat ambiguous, though I have no doubt that those more familiar with music literature would not.

... There remains some doubt, however, concerning the desirability of attempting to distinguish between materials "intended to form part of the library's permanent collection" and those not so intended. What is wrong with counting them when added and deducting them when withdrawn? This obviates the necessity of a crystal ball in predicting what is to be permanent, and also simplifies the instructions to those doing the actual counting. 